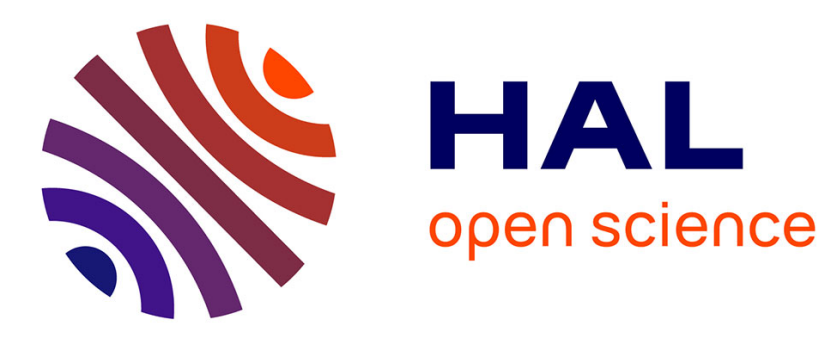

\title{
Real Options Theory for Law Makers
}

Marie Obidzinski, Bruno Deffains

\section{To cite this version:}

Marie Obidzinski, Bruno Deffains. Real Options Theory for Law Makers. Recherches Economiques de Louvain - Louvain economic review, 2009, 75 (1), pp.93-117. 10.3917/rel.751.0093 . hal-00447170

\section{HAL Id: hal-00447170 https://hal.science/hal-00447170}

Submitted on 14 Jan 2010

HAL is a multi-disciplinary open access archive for the deposit and dissemination of scientific research documents, whether they are published or not. The documents may come from teaching and research institutions in France or abroad, or from public or private research centers
L'archive ouverte pluridisciplinaire HAL, est destinée au dépôt et à la diffusion de documents scientifiques de niveau recherche, publiés ou non, émanant des établissements d'enseignement et de recherche français ou étrangers, des laboratoires publics ou privés. 


\title{
Real Options Theory for Law Makers*
}

\author{
Bruno Deffains ${ }^{\dagger}$ and Marie Obidzinski ${ }^{\ddagger}$
}

\begin{abstract}
The formulation of legal rules is a challenging issue for lawmakers. Trade-offs are inevitable between providing more guidance by specific rules and enlarging the scope by general rules. Using real options theory we show that the degree of precision should be considered as a degree of flexibility which increases the value of the text. Thus, we derive a normative principle for a draftsman to choose between rules versus standards and to decide when the law should be enacted. In highly innovating environments, delaying the enactment allows lawmakers to obtain more information. Therefore, the lower the degree of precision of the law, the shorter the delay.
\end{abstract}

Key words: Degree of precision, flexibility, obsolescence, rulemaking JEL classification: C61, G12, K00, K40.

\footnotetext{
${ }^{*}$ We are indebted to Emanuela Carbonara, Claude Fluet, Thierry Burger-Helmchen, Giuseppe Dari Mattiacci, Eric Langlais, Paul Mahoney, Jenny Monheim, Francesco Parisi, Stéphane Saussier, Tanguy van Ypersele, Richard Zerbe for useful comments. We would like also to thank the participants in the 2004 conference of the European Association for Evolutionary Political Economy, the 2004 Deutsch-Französiche Gespräche in der ökonomischen Theorie des Rechts at Humbolt- Universität zu Berlin and the 2005 conference of European Association for Law and Economics Annual Meeting. All errors remain our own.

${ }^{\dagger}$ BETA - UMR CNRS and University of Nancy- 13, place Carnot, F-54035 Nancy, France (E-mail address: bruno.deffains@univ-nancy2.fr).

${ }^{\ddagger}$ Corresponding author: BETA - UMR CNRS and University of Nancy - 13, place Carnot, F-54035 Nancy, France (E-mail address: marie.obidzinski@univ-nancy2.fr).
} 
"Ceux qui ont un génie assez étendu pour pouvoir donner des lois à leur nation ou à une autre doivent faire de certaines attentions sur la manière de les former" Montesquieu, 1748, De l'Esprit des Lois, Livre XXIX, Chapitre XVI

\section{Introduction}

The design of legal rules is a challenging issue for legislators. The prime aim of these rules is to capture the objective of underlying policies. However, lawmakers are unable to foresee all contingencies and citizens might be misguided by ambiguous rules. As expressed by Landes and Posner (1975:879):

"the limits of human foresight, the ambiguities of language, and the high cost of legislative deliberation combine to assure that most legislation will be enacted in a seriously incomplete form, with many uncertainty left to be resolved by the courts".

Naturally, these difficulties grow with social and technological changes that generate new uncertainties.

This paper aims to determine how much uncertainty should be left to courts. Lawmakers decide this by choosing the following characteristics of legal rules (Kaplow, 1992, 1999): the degree of precision and whether the content of law should be given at the time of enactment (rule) or by the judge (standard). A trade-off is inevitable between providing more guidance by specific rules and enlarging the scope by general rules. This choice depends on the variability of contingencies and on the degree of innovation in the area of the law. The latter relates to the process of obsolescence: times goes by and the rule that was designed for its context at the time of enactment does no longer fit reality. In other words, these characteristics are chosen according to how much information the lawmaker believes he receives.

Variable contingencies tip the scale towards more flexible rules. Lowering specificity in order to increase flexibility bears a cost: benefits in terms of guidance diminish, and uncertainty as regards interpretation rises. Regulation versus ex post liability is a classical example where the variability of circumstances influences the choice between rules and standards. Regulation guides firms to stick to a uniform standard of care while ex post liability gives the judge the possibility to define the optimal standard of care as a function of each particular case. 
Hart (1994:130) highlights this issue:

"In fact all systems, in different ways, compromise between two social needs: the need for certain rules which can, over great areas of conduct, safely be applied by private individuals to themselves without fresh official guidance or weighing up of social issues, and the need to leave open, for latter settlement by an informed, official choice, issues which can only be properly appreciated and settled when they arise in a concrete case".

A typical example of obsolescence is the creation of the rule on disclosure of information in the financial sector as described by Pistor and Xu (2002a, 2002b, 2003). The underlying policy objective is that firms that trade on the stock exchange should disclose all relevant information to shareholders in order to ensure an efficient functioning of the market. However complex financial products evolve so rapidly that it is not possible to specify all possibilities in statutory law. Consequently, the lawmaker has to compromise between the guidance benefits of precise rules and a lower depreciation rate of general standards. The sensitivity to obsolescence decreases with the "spectrum" of the legal rule. Many other examples can be found in new areas of law, such as genetics, biotechnologies, the internet or music piracy. Law must fit reality, that is it must adapt itself to the uncertain evolution of its environment.

This paper studies how to deal with varying contingencies and obsolescence by using real options theory. In theoretical terms, lawmakers have different options ${ }^{1}$. They can increase the degree of flexibility of a rule. They can also delay promulgation. Finally, they can choose an optimal mix between a delay and the precision of the rule.

The law and economics literature focuses on the relative costs and benefits of rules versus standards. Ehrlich and Posner (1974) develop a static analysis on the precision of legal rules. Precise rules are said to guide courts and the behavior of parties more efficiently before and during the trial, providing them with more complete information. This effect is included by Landes and Posner (1976) in an analysis of the creation of precedents as an investment decision. The set of legal precedents is treated as a stock of information $^{2}$ that depreciates when unforeseen contingencies arise. The existence of an optimal stock of legal capital is proven. It is derived from the maximization of the net present value (NPV) of the informational services minus the cost of investment. Future

\footnotetext{
${ }^{1}$ From this perspective, it is important to note that the paper does not distinguish between primary and secondary lawmaking, i.e. between legislation and regulation.

${ }^{2}$ On the informational value of legal rules, see also Diver (1983), Kaplow (1992, 1995, 1999), Mahoney and Sanchirico (2004).
} 
benefits are implicitly supposed to be certain and general legal capital is assumed to have a lower depreciation rate than specific legal capital ${ }^{3}$. An empirical analysis on citations of laws during litigation shows that general rules tend to depreciate more slowly. Therefore, the greatest benefit of standards can only be perceived by introducing a time dimension: its adaptability to a large set of circumstances. Ehrlich and Posner (1974) further observe that a standard enables the legal outcome to change over time when the economic and technological environment changes. The counterpart of these advantages is that precision is costly because courts have to collect a lot of information before formulating and applying rules.

To assess the value of law, one limit of the NPV criterion used by Landes and Posner (1976) is that it does not permit to take into account the uncertainty which characterizes the evolution of the value of the contents of a legal statement. A "content" is defined here as an interpretation, a meaning of the statement (Kaplow, 1992). A standard such as adopting "reasonable care" has multiple contents determined by ex post contingencies, while a rule generally has only one. The value of a content varies with the disparities of situations.

Very recently, the method of pricing legal options has been applied to legal frameworks (Ayres, 2005, Bar-Gill, 2005, Grundfest and Huang, 2004) in order to capture uncertainty from the agents' point of view (litigants, potential offenders). Parisi, Fon and Ghei (2004) took the point of view of lawmakers and proposed a model of investment under uncertainty applied to the timing of the decision to invest in law. They show that there is a value to waiting in lawmaking.

However, the question of flexibility on the choice of the ex post legal content has not been analyzed using the real options framework. The specificity of our approach lies in the use of real options to analyze the characteristics of legal rules. In a first step we evaluate flexibility regarding the ex post choice of content, and a decision making rule is derived to choose between a rule as opposed to a standard. In a second step, the flexibility of the timing of enacting the rule is evaluated and a decision rule for the lawmaker to choose when to enact a law is derived as a function its degree of precision. This framework helps to understand how legal systems cope with the incompleteness of law. In doing so, it sheds a different light on the debate about the characteristics of legal rules by using real option theory.

The paper is structured as follows. Section (2) justifies the interpretation of legal rules as real options. Section (3) evaluates the flexibility of standards. Section (4) shows that

\footnotetext{
${ }^{3}$ See also Posner (1999), for a analysis of legal rules from an evolutionary perspective.
} 
the sensitivity of legal rules to obsolescence affects the value of waiting in lawmaking.

\section{Legal rules as real options}

How should a producer of law evaluate legal rules? What characteristics should be chosen in an evolving environment? An original way to analyze these choices is to consider legal rules as real options. Dixit and Pindyck (1994) notice that real option theory can be applied to many non-economic issues and particularly to legal reforms ${ }^{4}$. In this section, the real option framework is briefly reviewed and the relevance of its application to the issue of obsolescence in lawmaking is discussed.

\subsection{Dynamics of the real options approach}

After the simultaneous success of Merton (1973) and Black and Scholes (1973) in the early seventies, real option theory marked a great progress in the domain of investment decisions in corporate finance. Under this approach, the value of a firm or a project is not only the sum of the value of the current assets but also the value of the future opportunities to invest. Furthermore, while the classical NPV criterion implicitly assumes that the future value of the investment is known, option theory introduces the cost of uncertainty in the evaluation of projects. Uncertainty is formalized by the assumption that the underlying asset price follows a stochastic process. Indeed, the price of each of these underlying opportunities, such as the price of commodities or the demand level on a particular market, varies stochastically and is consequently impossible to forecast.

In order to apply real options theory, an investment project has to be characterized by the uncertainty on its future cash-flows, the irreversibility of its investments, and flexibility of the project. The latter refers to the ability to take advantage of favorable circumstances and to avoid unfavorable ones. The existence of an option value depends on flexibility. Many forms of flexibility exist and thus many types of real options have to be considered. Flexibility may lie in the possibility to delay the investment. Flexibility can also bear on the ex post choice of the type of output.

\footnotetext{
${ }^{4}$ See Pindyck and Dixit (1994), p. 23-25. They particularly focus on the value of waiting in lawmaking: "Given some legislative and administrative costs of changing laws, our theory suggests that the option to wait and see if the trend of opinion will reverse itself has some value".
} 


\subsection{Legal options and lawmaking}

As an investor, the lawmaker ${ }^{5}$ compares the relative costs and benefits of the different formulations of legal rules. The costs and benefits of rules compared to standards depends on the variability of contingencies and on the degree of innovation in the environment. Indeed, legal rules provide a flow of services, such as informational benefits about the way to behave in human interactions ${ }^{6}$. From a static point of view, the law and economics literature emphasizes the fact that specific rules do better than general rules but that they are more costly to create. Posner (1992) remarks that precise rules reduce information costs of litigants and adjudicators during the trial. When matters are less clear and more difficult to predict, parties' expectations of the outcome of the adjudication are more likely to diverge. As a result, parties to a dispute will tend to settle less often and the litigation rate increases ${ }^{7}$. On the contrary, precise law provide more "guidance" and consequently increases the deterrent or preventive effects of legal rules. To sum up, when we consider the optimal design of rules, the flow of benefits from law comes from the ability to guide behavior and to avoid costs. Thus, the value of law is directly linked with its informational contents. The more precise the information is, the more parties and judges are informed before and during litigation, and the lower is the cost incurred by adjudicators.

Ehrlich and Posner (1974) analyze the relation between precision and efficiency of the legal process, showing that the degree of precision of a legal rule is the main determinant of the reduction of lawsuit costs, as it allows better guidance provided to courts. They recognize the importance of information costs, especially when the legal command potentially covers many different behaviors.

Obviously, this result may no longer be valid when a time dimension is added ${ }^{8}$. More precisely, facing significant changes in a given area, the law may not fit reality any longer. In such a case, the value of legal rules is reduced, since the flow of its services stops. Limits to human capacity and the ambiguity of terms prevent producers of rules from accurately and exhaustively listing all possible contingencies under which a rule is to be

\footnotetext{
${ }^{5}$ We assume that the lawmaker is a risk neutral benevolent investor. However, we are aware of the interest-group perspective that analyzes the influence of lobbies on the political process. In particular, precise legislation may reflect lobbies' preferences and limit the discretionary power of judges. See for example Stigler (1971), Landes and Posner (1975) and Mahoney and Sanchirico (2005).

${ }^{6}$ It is quite natural in the field of economics of contracts to consider that courts and legal systems contribute to solving moral hazard and adverse selection problems (see for instance Baker, Gibbons and Murphy, 1999 and the literature therein).

${ }^{7}$ See also Cooter et Rubinfeld (1989) on litigation versus settlement in a differing perception model, Johnston $(1991,1995)$ on bargaining under rules versus standard, and Spier (1994) on the impact of the design of damage awards in litigation versus settlements and on the ex ante level of care in an assymetric information model.

${ }^{8}$ Ehrlich and Posner (1974) remark that "we have largely ignored the cost and benefits associated with the time dimension of legal regulation" p. 278.
} 
activated. This kind of incompleteness is recognized as an issue that the creator of law has to deal with: it leads to deterrence problems which may only be taken into account in a dynamic perspective and not in a static one. However, according to their degree of precision, legal rules have different sensitivities to obsolescence. According to Ehrlich and Posner (1974), "obsolescence is not a serious problem with regulation by standards" and that "the more detailed a rule is, the more often it will have to be changed" 9 . In other words, a limit to obsolescence consists in choosing ambiguous terms. However, ambiguity implies divergent interpretations, and thus contributes to the incompleteness of law. What is important to note is that while both legal gaps and ambiguity define incompleteness of law (Bowers, 2000, Pistor and Xu, 2003), ambiguity is included intentionally in the law. Indeed, ambiguous terms present some benefits that are highlighted in the real options approach described in the next section.

Moreover, the costs of enacting a precise law are higher than the enactment costs generated by a general law. Indeed, legislators have to find an agreement on more points (Posner, 1992). Following Kaplow $(1992,1999)$, informational costs are incurred ex ante by the producer of law in the case of rules while they are incurred ex post by the adjudicator in the case of standards.

When considering legal rules as real investments, two types of options have to be considered. First, while a rule may be compared to a bright line test completely cut off from any circumstantial factor, a standard allows the judge to choose the most relevant interpretation among many other. This flexibility, arising from the additional possibility of choosing, not only to apply one particular content but to apply the most valuable content, can be evaluate by using a particular type of option; "an option on the maximum on multiple risky asset". This idea underlying this option is very intuitive. For example, imagine that a field is bought in $t_{0}$ and that the investor has to choose in $t_{1}$ to build different types of productive units. The one with the highest value will be chosen in $t_{1}$, knowing that their respective values evolve stochastically. The option formula, developped by Stulz (1982) for two assets and by Johnson (1987) on several assets evaluate the flexibility arising from this ex post choice. This idea is easily transposable to law. Imagine a legal statement using ambiguous terms such as "a driver should not impose an unreasonable risk to pedestrians". This terminology allows many interpretations according to circumstances. The judge may punish a driver on the basis of the speed, on the basis of level of alcohol in the blood or regarding more general care such as using a mobile phone. On the contrary, a rule allow the judge to sanction only on the basis of one of these content, such as a speed

\footnotetext{
${ }^{9}$ Id. est.
} 
limit $^{10}$ as its content is given ex ante. Consider a traffic law putting the speed limit at $130 \mathrm{~km} /$ hour on motorways. The judge applies it if the driver exceeds the speed limit. In terms of option, this refers to a simple call option ${ }^{11}$ : the option is exercised at the time of the judgement only if the value of the underlying asset exceeds the cost to exercise it (the adjudication cost) which is equivalent to say that the law is not applied if not relevant.

Second, flexibility on the timing of the enactment is also valuable. The lawmaker has the ability to choose to wait before creating law in order to collect more information. However, the waiting depend on the degree of precision of rules.

\section{The trade-off between guidance and flexibility}

The choice between rules and standards is a familiar one to lawyers. The question generally involves a tradeoff between: (a) Invest more at T0, create a specific rule, and then invest at $\mathrm{T} 1, \mathrm{~T} 2, \ldots$ to update the rule or suffer the cost of obsolescence and (b) Invest less at T0, create a flexible standard, and then invest at $\mathrm{T} 1, \mathrm{~T} 2, \ldots$ to apply the standard.

In practice, legal norms can dictate particular outcomes or set forth more open-ended tests, whose application is left to the discretion of judges. For instance, speed limit may take the form of a rule requiring drivers to go no more than 130 kilometers per hour, or a standard requiring them to travel at a safe speed. On one side, we want laws to be clear so that agents exactly know what behavior is expected (guidance). This argues in favor of a rule. Considering the case of copyright law, we want to know who owns what, for how long, how far the copyright owner's rights reach, which unauthorized uses are excused or authorized. On the other side, we want judicial decisions to be adapted to facts, what pleads in favor of a standard.

We propose to explain how options theory could help to solve this trade-off. Using a numerical example, we propose to evaluate the flexibility of legal rules via options theory and to derive a decision rule.

\subsection{Valuation of legal flexibility}

The fluctuations of a legal content value are assumed to be uncertain because new informations arise as time goes. Appeals to pharmaceutical or medical liability rules is affected by the state of the art concerning risks management. The necessity of bankruptcy law is dependant of the macroeconomic growth. The use of labor law is certainly influenced by

\footnotetext{
${ }^{10}$ We are aware that this example is very simplified. The aim is to highlight the flexibility to choose among multiple content rather than among a more limited number of interpretation.

11 "Call" as the adjudicator has to estimate the cost to have the possibility to apply the law.
} 
the unemployement rate. Therefore, the value of the legal contents generally grows over time with the growth of the economy, however in an uncertain way. To capture this idea, we consider that the value $S$ of a legal rule follows a standard Brownian motion ${ }^{12}$. An increase $d S$ during the interval of time $d t$ is characterized by:

$$
d S=\mu_{S} d t+\sigma_{S} d z
$$

where $\mu_{S}$ and $\sigma_{S}$ are two constant terms. The increment $d z$ follows a Wiener process, that is $d z=\varepsilon \sqrt{d t}$, with $\varepsilon \sim N(0,1)$. The standard deviation $\sigma_{S}$ characterizes the volatility of $S$, i.e. the variability of contingencies. The constant term $\mu_{S}$ is the drift, that is the part of the change $d S$ which is predictable.

The possibility to apply a legal rule can be evaluated by a European call option ${ }^{13}$. The Black and Scholes formula for this option is:

$$
C\left(S_{i}, K, T\right)=S_{i} N\left(d_{1}\right)-K e^{-r T} N\left(d_{2}\right)
$$

with

$$
\begin{gathered}
d_{1}=\frac{\log \left[\frac{S_{i}}{K}\right]+\left(r+\frac{\sigma_{i}^{2}}{2}\right) T}{\sigma_{i} \sqrt{T}} \\
d_{2}=d_{1-} \sigma_{i} \sqrt{T}=\frac{\log \left[\frac{S_{i}}{K}\right]+\left(r+\frac{\sigma_{i}{ }^{2}}{2}\right) T}{\sigma_{i} \sqrt{T}}
\end{gathered}
$$

$K$ is the strike price of the call option ${ }^{14}$, that is the cost of the judge's decision (or the cost to enforce a legal rule) and $T$ the time of the judgement, and $S_{i}$ the initial value of the content $i$. We assume that $\mu_{S}$ equals $r$; the risk free rate. The lawmaker is assumed to be risk neutral. Therefore, optimal allocation of lawmaking resources requires that $\mu$ equals the risk free $r . N(x)$ is the cumulative function of a variable $x$ which follows a standardized normal distribution $N(0,1)$.

To illustrate, we consider that at date 0 the content of law is estimated via the value of conflicts solved by the intervention of the judicial system (including agreements in the shadow of the law). Suppose that $S=40$ millions euros. The cost to apply the law $K$, that is the cost of legal inputs, is also set equal to 40 millions euros. Consider now that at date $T=10$, the court will apply the rule if the content value $S_{10}$ is higher than $K$.

\footnotetext{
${ }^{12}$ This type of Brownian motion is generally used to characterized the fluctuations of raw materials prices. Black and Scholes formulas applied below are based on this hypothesis.

${ }^{13}$ This type of option is called "European" as the time $T$ to strike the option is fixed, while the date to strike "American" options is not specified in advance.

${ }^{14}$ For simplicity, we assume here that the cost of the judge' decision is the same with a standard and with a rule. In reality, the cost incurred by the judge in interpreting a fuzzy standard rather than applying a simple rule might be more important.
} 
The volatility of the content value is suposed equal to 0.3 , and the risk free rate to 0.1 . The parameters values capture the quite reasonable idea that the benefits of the rule are significantly positive and that the interest rate is small.

Under these hypothesis, the legal value of the rule is given by ${ }^{15}$ :

$$
C(40,40,10)=26.89
$$

The possibility to apply the rule at date $T$ is valued at 26.89 millions euros. To give an economic interpretation to this value, we need to compare with the one obtained for a standard using the same numerical values.

To simplify calculations, assume that there are only two possible interpretations of a standard (i.e. two contents $A$ and $B)^{16}$. Under a standard, the judge has to choose the maximum between $S_{A}, S_{B}$ and 0 at the date of the judgement. Assume that the ex ante value $S$ of two contents is the same: $S_{A}=S_{B}$. The value of the call on the maximum of $S_{A}$ and $S_{B}$ can be calculated using the following formula ${ }^{17}$ :

$$
M X\left(S_{A}, S_{B}, K, t\right)=C\left(S_{A}, K, t\right)+C\left(S_{B}, K, t\right)-M\left(S_{A}, S_{B}, K, t\right)
$$

with $C\left(S_{A}, K, t\right)$ and $C\left(S_{B}, K, t\right)$ corresponding to the ordinary calls on $S_{A}$ or $S_{B}$ and $M\left(S_{A}, S_{B}, K, t\right)$ to the option on the minimum between $S_{A}$ and $S_{B}$.

The calculation of $M X$ implies to appreciate the degree of correlation between the two contents $\rho_{S_{A}, S_{B}}$. Positive correlation seems justified by the fact that the two possible interpretations are generally linked. For example, regarding the legal statement on the unreasonable risk, at least two contents "do not drink alcohol" and "do not exceed 90 kilometers per hour" can be found. These two contents are linked if alcohol is associated with high speed. Following, we suppose that the degree of correlation is set at 0.5 .

Call options on the maximum of two risky assets have to be evaluated in two steps. First, the value of a european option on the minimum of two assets $M\left(S_{A}, S_{B}, K, t\right)$ is calculated. Then, the value on the maximum $M X\left(S_{A}, S_{B}, K, t\right)$ is deduced. For the

${ }^{15}$ By substitution, we find $(2)$ and $(3)$ :

$$
\begin{aligned}
& d_{1}=1.52 \\
& d_{2}=0.57
\end{aligned}
$$

We can use a polynomial approximation to calculate $N(d)$ and get: $N\left(d_{1}\right)=0.93$ and $N\left(d_{2}\right)=0.71$.

${ }^{16}$ For simplicity reason, we calculate the option for two possible assets. The results are transposable to multiple assets options, as the increase of the number of asset increase the value of the option.

${ }^{17}$ See Stulz (1982) 
parameters values given above, we found that :

$$
M\left(S_{A}, S_{B}, K, t\right) \simeq 12.87
$$

\section{See Appendix 6.1}

The possibility to apply the content of the rule which have the minimum value (the interpretation of the rule which fits the less to the case) at date $t$ is valued at 12.87 millions euros. The intuition is the straightforward : the possibility to apply the standard is better than nothing.

As the initial values of both contents are equal, we get $C\left(S_{A}, K, t\right)=C\left(S_{B}, K, t\right)$ and the value of the call on the maximum of $S_{A}$ and $S_{B}$ approximately amounts to:

$$
M X\left(S_{A}, S_{B}, K, t\right) \simeq 40.91
$$

The comparison between the ordinary option $C_{i}$ and the option on the maximum $M X$ shows that the value of law increases with the number of possible ex post contents: a standard has a higher value than a single rule ${ }^{18}$. The difference between $M X$ and $C$ represents the value of flexibility induced by the choice between two contents and not only one.

This approach contributes to justify the choice of general standard like the reasonable man and bonus pater familias in liability law or bona fide in contract law. These standard have so many legal interpretations that the call on the maximum is very high.

Naturally, the scope of a standard consists in the number $n$ of contents $S_{i=1, . ., n}$ and in the strength of their links, that is the degree of correlation. The lower the correlation between contents, the larger the scope of a standard. For a correlation $\rho_{S_{1}, S_{2}}$ reduced to 0.25 , the option on the maximum of $S_{1}$ and $S_{2}$ approximately amounts to:

$$
M X\left(S_{1}, S_{2}, K, t\right)=44.49
$$

This establihes the relevance of the scope of a standard. The larger the scope, the higher the standard value.

This first step in the analysis of legal rules in the real options framework emphasizes the value of flexibility compared to the rules' rigidity in an uncertain environment. The value of flexibility should be taken into account by lawmakers when dealing with changing

\footnotetext{
${ }^{18}$ Obsviously, a lawmaker should compare the value of many rules with a standard. However, a lawmaker may not be able to foresee every contingencies (and be aware that there exist unforeseeen contigencies) or it may be too costly to write a rule for each one. In this case, the comparison of a single rule with a standard is relevant.
} 
and complex areas of law. Such result does not question the benefits of precision in terms of guidance, but highlights the "adaptability" of general standards. Indeed, standards allow judges to adapt legal rules to circumstances and to manage the obsolescence of law. If changes arise and the value of a specific content is strongly reduced, the judge still have in hands opportunities to adapt contents ${ }^{19}$.

\subsection{The lawmaker decision rule}

In a second step, we propose a formalization of the trade-off between rules and standards by taking into account a major benefit of rule in term of "guidance". In our approach, more flexibility is provided at the cost of less informational value. The difference between $M X$ and $C$ captures the value of flexibility. Let $\gamma$ captures the lower ex ante informational benefits brought by standards compared to those brought by rules, as discussed in section (2). $\gamma$ varies between 0 and 1 , such that $\gamma \in(0 ; 1)^{20}$. When $\gamma$ is closed to zero, the ex ante informational benefits of a standard are very low. On the contrary, $\gamma$ close to the unity characterized a legal statement which brings many information how to behave, and thus very much certainty.

To make easier the comparison, we assume that the initial value of both statements are the same: $S_{1}=S_{2}$. So, we have: $C\left(S_{1}, K, t\right)=C\left(S_{2}, K, t\right)=C\left(S_{i}, K, t\right)$. Thereby, a legislator should favor a standard rather than a rule if $\gamma M X\left(S_{1}, S_{2}, K, t\right)>C\left(S_{i}, K, t\right)$, with $i=1,2$. The following proposition is derived:

Proposition : There exists a threshold value $\bar{\gamma} \in\left[\frac{1}{2}, 1\right)$, above which the lawmaker should enforce a standard rather than a rule. Everything else remaining equal, the threshold value $\bar{\gamma}$ equals $\frac{C\left(S_{i}, K, t\right)}{M X\left(S_{1}, S_{2}, K, t\right)}$.

Proof: see Appendix 6.2

This proposition can be interpreted as a decision rule for lawmakers. In order to choose between a standard or a rule, the lawmaker has to compare the flexibility and the guidance values. The lower $\frac{C\left(S_{i}, K, t\right)}{M X\left(S_{1}, S_{2}, K, t\right)}$, the higher the value of flexibility. If the informational benefits of a standard are too low $\left(\gamma<\frac{1}{2}\right)$, a rule is always preferred. The society valuation of guidance $(\gamma)$ depends on the agents' degree of risk aversion. They may prefer the rule has with certainty a meaning $S_{1}$ rather than an ex post interpretation $S_{1}$ or $S_{2}$, at the cost of more rigidity. The higher the degree, the higher the valuation of law guidance. If $\frac{1}{2}<\gamma$,

\footnotetext{
${ }^{19}$ Although light carts have disappeared, a statement requiring a driver to adopt "a reasonable speed" is still adapted for motor vehicle, while a statement setting a particular speed would have become obsolete. This issue of obsolescence is further developed in section (4).

${ }^{20}$ The value of the informational benefits brought by the agent is never as high as the value of the informational benefits brought by a rule.
} 
the lawmaker has to balance the relative advantage of both type of legal statements. If $\gamma<\frac{C\left(S_{i}, K, t\right)}{M X\left(S_{1}, S_{2}, K, t\right)}$, a rule is preferred to a standard. On the contrary, if $\gamma>\frac{C\left(S_{i}, K, t\right)}{M X\left(S_{1}, S_{2}, K, t\right)}$, the value to flexibility of a standard is sufficiently high to tip the balance in favor of the standard.

For instance, considering the case of patent or copyright laws, one can consider that the informational benefits of a standard are too low $\left(\gamma<\frac{1}{2}\right)$, so that a precise rule is needed. A possible explanation is that the benefits of a general standard of fairness are small in a context of fast innovation where firms need before all precise informations about the extent of the protection they will obtain for a certain period.

However, until now, we assert that precise rules have a higher informational value than standards. However, precise rules are also more sensitive than standards to innovation. This is due to their lack of flexibility. Therefore, a benevolent lawmaker has to take into account the risk of obsolescence in the evaluation of the rule. In a highly innovating context, the producer of law may decide to wait before investing in law in order to obtain more information or to invest in a large scope standard. The effect of such characteristics on the choice to invest in law or wait in order to get more information is developed in the following section.

\section{Enactment timing and legal precision}

In the preceding analysis, we have considered legal rules as European options: the time to exercise the option is fixed in advance. However, the lawmaker may decide to wait before creating the law in order to get more information about the area. In this case, the option is called "American": The time $t$ of exercising "American" options is not fixed $(t \leq T)$. Applying a model of investment under uncertainty in continuous $\operatorname{time}^{21}$, it is possible to show that there is a value of waiting in lawmaking (Parisi and al., 2004).

In the analysis below, we consider that legal systems are subject to obsolescence inherent to social and/or technological evolution ${ }^{22}$. Jones and Ostroy (1984) show that the value of flexibility depends on the amount of information the decision maker expects to acquire. They discuss the notion of beliefs and propose the following behavioral principle: "the more variable are the decision makers' beliefs, the more flexible is the position he will choose... current doubts may be partially resolved in the near future. This prospect decrease the attractiveness of the long-term commitment, in that one is able to respond less

\footnotetext{
${ }^{21}$ This type of model was first developed by McDonald and Siegel (1986)

${ }^{22}$ In the model, innovation is assumed to be exogeneous and not an output of an active research by agents looking for news technologies that enable them to avoid the law (Malik, 1990).
} 
fully to new information". We can observe the same situation in the legal environment. The lawmaker has generally two possible stratgies: to wait until he obtains "enough" information to enact a precise rule (that is, the value of the legal content is "sufficient") or to adopt a more general rule.

\subsection{Variation of legal content value under obsolescence}

To capture the idea that obsolescence may happen at a time non determinable previously, it seems more accurate to use a Poisson process (Dixit and Pindyck, 1994, and Piatecki, $2004)^{23}$. Thus, we assume that $S$ follows a mixed Brownian motion jump process such as:

$$
d S=\alpha S d t+\sigma S d z-\phi S d N
$$

where $d N$ is the increment of a Poisson process. There is a probability $\lambda$ that an event occurs in the interval $d t$.

$$
\begin{aligned}
& \operatorname{Pr}(d N=1)=\lambda d t \\
& \operatorname{Pr}(d N=0)=1-\lambda d t
\end{aligned}
$$

If an event occurs, the value $S$ of the legal content drop by a fixed percentage $\phi$ during the period $d t$, with $0 \leq \phi \leq 1$. If $d N(t)=\phi d t$, the value of the benefits decrease from $\phi$ times its initial value. We find:

$$
d S=(\alpha-\phi) S d t+\sigma S d z
$$

If $\phi=1$, the legal rule creates some benefits and loses them immediately, and then creates no more benefits:

$$
d S=\alpha S d t+\sigma S d z-S d t
$$

The mixed Brownian jump process describes situations where a loophole is found in law and every potential offender circumvents the law. A good illustration refers to the evolution of environmental liability when firms adopt strategies to escape the payment of damages in case of judgement proof (LoPucki, 1996).

The mixed Brownian motion jump process is partially predictable as the expected rate of change $E(d N)$ is different from zero, with $E(d N)=\phi \lambda d t$ and $V(d N)=\phi \lambda d t$. The expected change of $S$ is not $\alpha$ but instead $E(d S)=(\alpha-\phi \lambda)$, as on each interval $d t$, there

\footnotetext{
${ }^{23}$ The representation of the evolution of benefits with a Brownian motion necessarily implies that the legal rule exists and yields benefits for ever. Consequently, the formalization of the evolution of the benefits $S$ as a Brownian motion is not suitable with the possibility of obsolescence.
} 
is a probability $\lambda d t$ that $V$ will fall by $100 \phi$ percent $^{24}$.

As $N(t)$ follows a Poisson distribution, the probability of an event to happen during one period $d t$ is independent from the probability of an event happening in any other period. Furthermore, $d z$ and $d N$ are independent, that is $E(d z d N)=0$.

\subsection{Enactment timing}

The risk-neutral lawmaker decides at each period $d t$ whether to exercise the option, that is to promulgate the rule, or to continue waiting. The decision to invest resources in law can be made at any period and can be indefinitely postponed. The lawmaker chooses the maximum between the net benefits $S(t)-I$ and the present expected value of the option $1 /(1+r) E[F(S, t+d t)]$, that is between the left part and the right part of the Bellman equation (6).

$$
F(S)=\max \left\{S(t)-I ; \frac{E[F(S, t+d t)]}{1+r}\right\}
$$

where $I$ is the sunk cost to implement the rule $\mathrm{e}^{25}$ and $r$ the risk free interest rate.

If there exists no such thing as obsolescence we have: $r=\alpha+\delta$, with $\delta$ the short term benefits. $\delta$ have to be included as it is the short term benefit of the rule, that is what benefit the rule would brought if it was enacted at time $t$. Indeed, as any asset, a rule has a return in the current period. However, if there exists even a slight probability $\lambda$ of obsolescence we have: $r=\alpha+\delta-\lambda \phi$.

The lawmaker can invest in two ways: a specific rule or a general rule. When decided, the enactment is immediate for both types of rules. Following Ehrlich and Posner $(1974)^{26}$, we assume that sensitivity to obsolescence is higher for precise rules than for general rules, that is:

$$
\lambda_{S} \leq \lambda_{R}
$$

with $\lambda$ the probability that an event occurs in the interval $d t$ which imply obsolescence, that is which decreases the value of the precise rule $R$ or the general general rule $S$ by the same fixed percentage $\phi$. In order to characterize obsolescence which would imply to change the rule, as said by Ehrlich and Posner (1974), $\phi$ is assumed to be equal to one.

Furthermore, informational benefits $\alpha+\delta$ are higher for precise rules rather than for

\footnotetext{
${ }^{24}$ Of course, one can imagine intermediate situation where the obsolescence is not so radical but, our aim is to consider the kind of tradeoffs that the rulemakers have to solve.

${ }^{25}$ We assume that $I$ is equal for a particular law at all times. This hypothesis is realistic if we consider that the decision to invest in law should not last too long so as to modify both institutional and informational costs.

${ }^{26}$ See Section 2.2 for a longer discussion.
} 
general rules as illustrated in section $2.2: \alpha_{S}+\delta_{S}<\alpha_{R}+\delta_{R}$, with $\alpha_{S}$ and $\delta_{S}$ the long term and short term benefits of a standard and $\alpha_{R}$ and $\delta_{R}$ the long term and short term benefits of a rule. To understand this, make the purely theoretical assumption that both type of law, which regulate the same area, have "initially" the same value. A small variation $d t$ increase more the value of the precise rule than the standard as $\alpha_{S}<\alpha_{R}$. Why is that? This is due to the fact that a precise rule provides more information than a standard, as discussed in section 2.2. For example, precises statements in driving regulation give more information on how to behave and make coordination easier than a standard which would state that "all motorist should drive carefully".

These informational benefits should compensate the expected loss due sensitivity to obsolescence $\lambda$. Indeed, the risk free rate $r$ has to remain constant, as shown by Merton (1976). Indeed, no producer of law would choose a precise rule if the negative risk effect is not counterbalanced by higher benefits: $r=\alpha_{S}+\delta_{S}-\lambda_{S} \phi$ and $r=\alpha_{R}+\delta_{R}-\lambda_{R} \phi$.

By dynamic programming, we obtain for $\phi=1$ :

$$
F(S)=A S^{\beta_{1}}
$$

with

$$
\beta_{1}=\frac{1}{2}-\frac{(r+\lambda-\delta)}{\sigma^{2}}+\sqrt{\left(\frac{r+\lambda-\delta}{\sigma^{2}}-\frac{1}{2}\right)^{2}+2 \frac{(r+\lambda)}{\sigma^{2}}}
$$

and with $A$ a constant term equals to:

$$
A=\frac{S^{*}-I}{\left(S^{*}\right)^{\beta_{1}}}=\frac{\left(\beta_{1}-1\right)^{\beta_{1}-1}}{\left(\beta_{1}\right)^{\beta_{1} I^{\beta_{1}}}}
$$

The optimal value $S^{*}$ is defined by:

$$
S^{*}=\frac{\beta_{1}}{\beta_{1}-1} I
$$

See Appendix 6.3

We observe that $S^{*}>I$, as $\beta_{1}>0$. The simple use of the NPV criteria is not sufficient: the threshold above which the legal content value is high enough to enact the rule is higher than the cost to promulgate it.

Using numerical values, table 2 illustrates how $\beta_{1}, S^{*}$ and $A$ vary with $\lambda$ and shows that the net effect of $\lambda$ over the critical value $S^{*}$ is positive ${ }^{27}$.

\footnotetext{
${ }^{27}$ The opportunity cost of investing immediately rather than waiting increases with the risk of obsolescence if the effect on the expected gain is neutralized by the increase in the rate of growth of benefits so as to keep constant the interest rate $r$.
} 


\begin{tabular}{|c||c|c|c|}
\hline$\lambda$ & $\beta_{1}$ & $S^{*}$ & $A$ \\
\hline \hline 0 & 2.000 & 2.000 & 0.250 \\
\hline 0.01 & 1.850 & 2.175 & 0.279 \\
\hline 0.02 & 1.732 & 2.366 & 0.307 \\
\hline 0.1 & 1.317 & 4.158 & 0.487 \\
\hline 0.3 & 1.124 & 9.062 & 0.677 \\
\hline 0.5 & 1.077 & 14.038 & 0.758 \\
\hline 0.7 & 1.055 & 19.027 & 0.805 \\
\hline 1 & 1.039 & 26.519 & 0.846 \\
\hline
\end{tabular}

Table 1 Values of $\beta_{1}, S^{*}$ and $A$ when $\lambda$ varies and $r=\delta=0,04, \phi=1, I=1$ and $\sigma=0,2$.

Figure 3 plots the waiting option value $F(S)$ as a function of the legal content value $S$. Suppose that $r=\delta=0.04, \phi=1, I=1, \sigma=0.2$. For a probability of obsolescence given as $\lambda=0.01$ for the standard, the coefficient $\beta_{1}$ amounts to 1.850 and the constant term $A$ to 0.279 . Equivalently, for $\lambda=0.1$ in the case of the rule, coefficients respectively are 1.317 and 0.487. Thus, the functions $F(S)=A S^{\beta_{1}}$ can be represented for a general rule and for a precise one. The upper curve refers to the precise rule option value. Promulgation costs $I$ are assumed to be equals for a rule and a standard. Consequently, a unique $S-I$ straight line is plot and tangency points with $\left.F(S)\right|_{S}$ and $\left.F(S)\right|_{R}$ gives threshold values $S_{S}^{*}$ and $S_{R}^{*}$

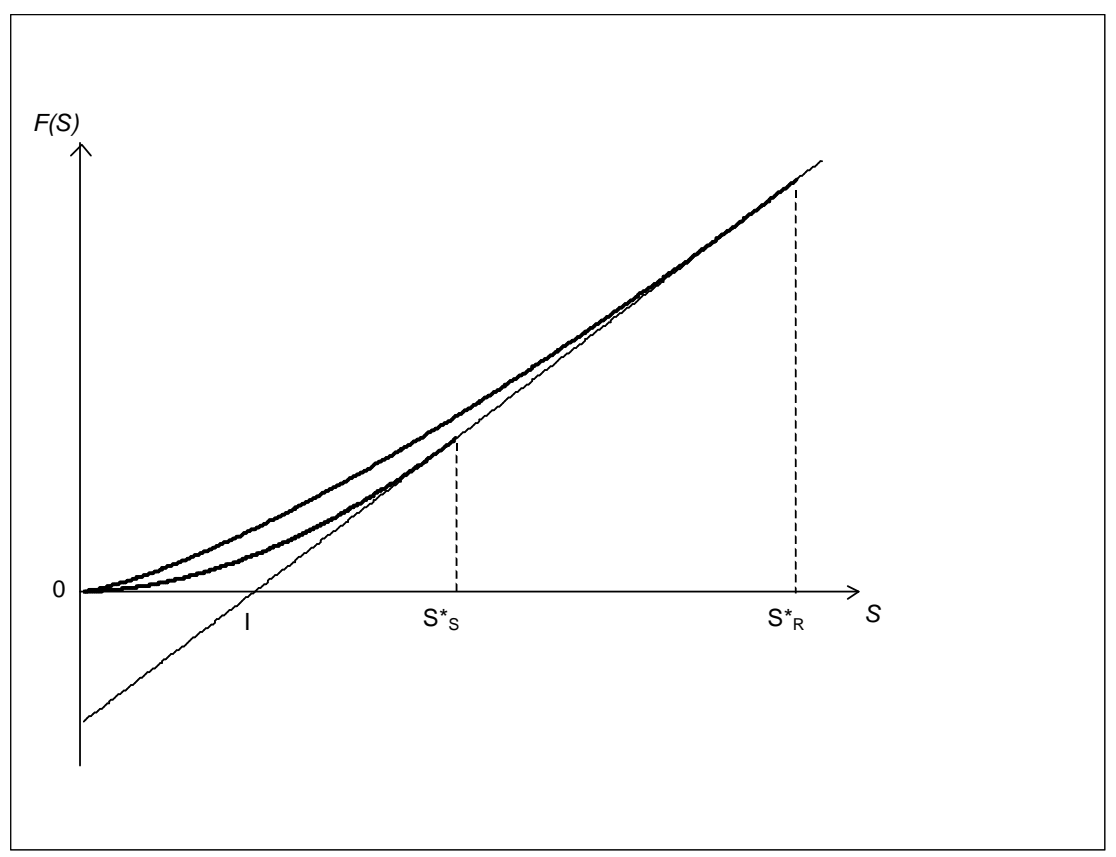


Figure 3: Threshold values for a standard $S_{S}^{*}(\lambda=0.01)$ and a rule $S_{R}^{*}(\lambda=0.1)$, with

$$
r=\delta=0.04, K=1, \sigma=0.2
$$

The figure should be interpret as the following. Each curve is not valid after the relevant threshold. On ]0, $S_{S}^{*}$ [ it is optimal to wait before investing in a standard as $F(S)_{S}>S-I$. At $S_{S}^{*}$, the lawmaker is indifferent between waiting and enacting a standard immediately. On $] S_{S}^{*}, \infty$ [, it is optimal to enact a standard immediately. The same reasoning applies for $S_{R}^{*}$.

Therefore, the optimal decision rule for a lawmaker is different under a precise and general rules and under innovating or quite stable environnement. If the probability of obsolescence is quite high (precise rule), the lawmaker should enact the law when the value of the legal content reach a higher level in comparison with the lower probability of obsolescence case (general rule). We also observe that the value of the waiting option is always higher for precise rule than general ones. It comes directly from the fact the condition which tells that the risk free rate $r$ has to remain constant. Higher risk have to be compensated by higher benefits.

Until now, we assumed that the sunk cost $I$ to implement the rule is equal for all types of legal rules. In practice however, this cost is generally higher for precise legal rule :

$$
I_{S} \leq I_{R}
$$

We can easily determine the effects of differences in costs using the same parametrization as before:

\begin{tabular}{|c|c|c|c|c|}
\hline$I$ & $\lambda$ & $\beta_{1}$ & $S^{*}$ & $A$ \\
\hline \hline 1 & 0.7 & 6.603 & 1.178 & 0.060 \\
\hline 1.1 & 0.7 & 6.603 & 1.296 & 0.035 \\
\hline
\end{tabular}

Table $2 r=\delta=0,04, \phi=1$, and $\sigma=0,2$. 


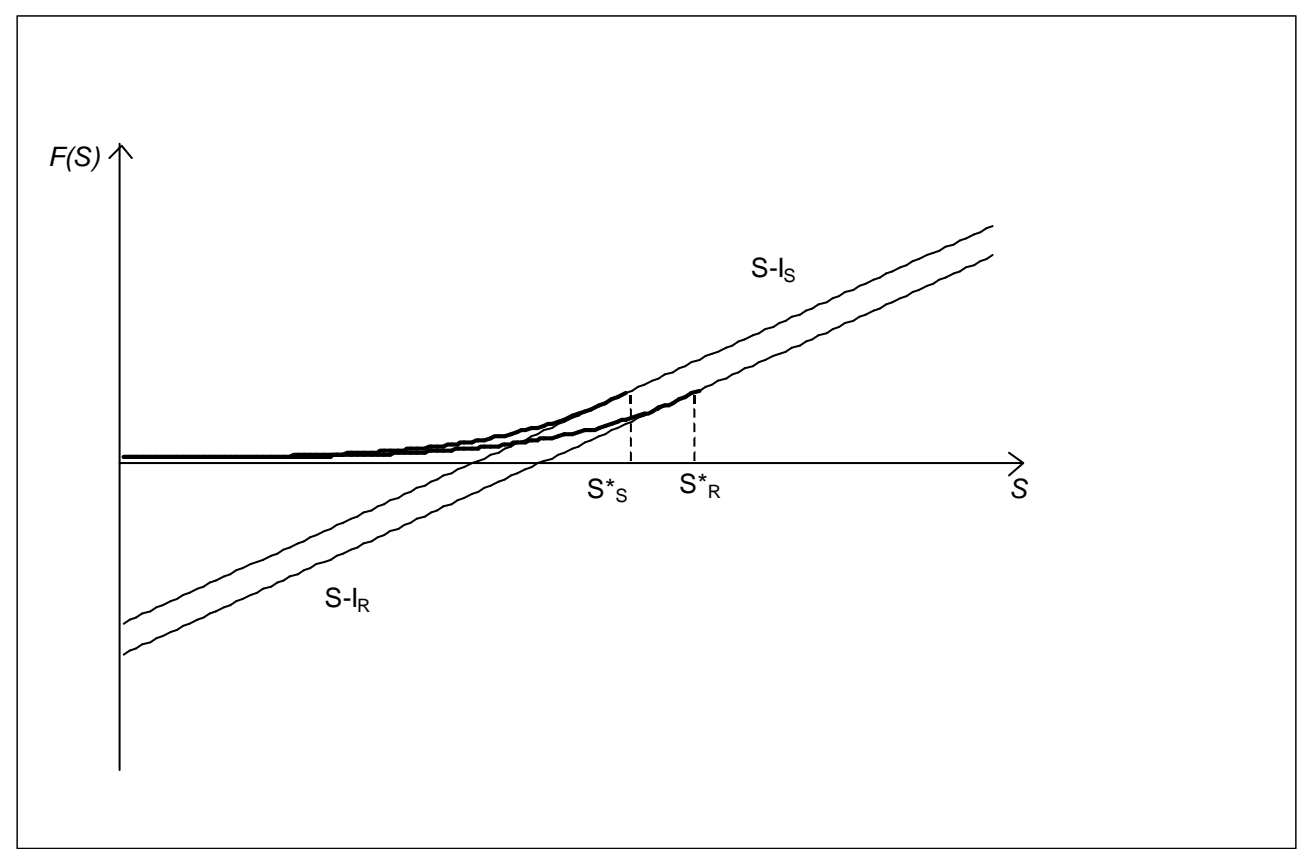

Figure 4: Threshold values for a standard $S_{S}^{*}(I=1)$ and a rule $S_{R}^{*}(I=1.1)$, with $r=\delta=0.04, K=1, \sigma=0.2$

Figure 2 shows that $S^{* 28}$ is negatively affected by the investment cost. Net benefits are also affected; $S-I_{R}<S-I_{S}$. Consequently, $S^{*}$ is higher if enforcement costs are higher.

To sum up, the threshold value for a precise rule is higher due to (1) a higher risk of obsolescence and (2) higher enforcement costs. The reason is that a standard is less costly to enact rapidly. Concerning the waiting option values, the comparison is more ambiguous. The conclusion will depend on the relative importance of enforcement costs and on the obsolescence intensity. The higher the obsolescence, the higher is the value to wait. The higher the cost of enforcement, the lower the value.

\section{Conclusion}

The use of the real options theory appears to be relevant as a guide for legal policies making.

From an theoretical point of view, lawmakers deal with constraints which are well

\footnotetext{
${ }^{28}$ Recall that

So that

$$
P^{*}=\frac{\beta_{1}}{\beta_{1}-1} \cdot I
$$

$$
\frac{\partial P(I)}{\partial I}=\frac{\beta_{1}}{\beta_{1}-1}>0
$$
}


captured by real options : uncertainty over the future services of legal rules, sunk costs of promulgation, and different types of flexibility in lawmaking and in the design of law.

We show that the precision of law can be justified: when the legal field is not subject to regular changes, the value of precise statement is justified. Complexity arises when laws have to be frequently modified due to innovation in the field. In this case, general statement should be preferred.

More generally, our paper tries to understand how a legal system copes with incompleteness of law, and to deal with the trade-off between potential gaps and ambiguous terms in law. It explores the aptitude of real options theory to look at characteristics of legal rules, to appreciate legal flexibility. The interaction between flexibility and the value of waiting in lawmaking is analyzed. Therefore, our framework wish to improving the conditions of public intervention regarding the drafting of legal rules. The approach allows to get a better picture of how legal rules deal with the issue of obsolescence. This framework is particularly well adapted to this question as it captures uncertainty inherent to economic life and, thus, the evolution of the value of services yielded by a legal rule.

From an empirical point of view, our paper calls for an evaluation of legal rules. This fundamental question, when resources are scarce, appears to be a current major concern. For instance, reports by the European Commission for the Efficiency of Justice (European Judicial Systems, 2006) and by the World Bank (Reports Doing Business) aim at collecting data on the organization of legal systems that could help to measure the value of legal rules and to apply real options approach. 


\section{APPENDIX}

\subsection{Estimation of a call option on the maximum of two legal contents}

The value of a European option on the minimum of two assets $M\left(S_{1}, S_{2}, F, t\right)$ is defined as

$$
M\left(S_{1}, S_{2}, K, t\right)=S_{1} N_{2}\left(\underline{\mathrm{d}}_{1}\right)+S_{2} N_{2}\left(\underline{\mathrm{d}}_{2}\right)-K \exp (-r t) N_{2}\left(\underline{\mathrm{d}}_{3}\right)
$$

with,

$$
\begin{aligned}
& d_{1}=\left[\gamma_{1}+\sigma_{S_{2}} \sqrt{t} ; \frac{\log \left(\frac{S_{1}}{S_{2}}\right)-\frac{1}{2} \sigma^{2} t}{\sigma \sqrt{t}} ; \frac{\rho_{S_{1}, S_{2} *} \sigma_{S_{2}}-\sigma_{S_{2}}}{\sigma}\right] \\
& d_{2}=\left[\gamma_{2}+\sigma_{S_{1}} \sqrt{t} ; \frac{\log \left(\frac{S_{2}}{S_{1}}\right)-\frac{1}{2} \sigma^{2} t}{\sigma \sqrt{t}} ; \frac{\rho_{S_{1} S_{2}} \sigma_{S_{2}}-\sigma_{S_{1}}}{\sigma}\right] \\
& d_{3}=\left[\gamma_{1} ; \gamma_{2} ; \rho_{S_{1}, S_{2}}\right]
\end{aligned}
$$

and ,

$$
\begin{gathered}
\sigma^{2}=\sigma_{S_{1}}^{2}+\sigma_{S_{2}}^{2}-2 \rho_{S_{1}, S_{2}} * \sigma_{S_{1}} * \sigma_{S_{2}} \\
\gamma_{1}=\frac{\log \left(\frac{S_{2}}{S_{1}}\right)+\left(r-\frac{1}{2} \sigma_{S_{2}}^{2}\right) t}{\sigma_{S_{2}} \sqrt{t}} \\
\gamma_{2}=\frac{\log \left(\frac{S_{1}}{S_{2}}\right)+\left(r-\frac{1}{2} \sigma_{S_{1}}^{2}\right) t}{\sigma_{S_{1}} \sqrt{t}}
\end{gathered}
$$

Assume that a couple of variables $(a, b)$ follows a standardized bivariate normal distribution. $N_{2}(\underline{\mathrm{d}})=M(a, b, \rho)$ is the cumulative probability of this standardized bivariate normal distribution, with $\rho$ the coefficient of correlation between the two variables: it is the probability that the first variable is less than $a$ and the second variable is less than $b$.

After having substituted $\sigma_{S_{1}}$ and $\sigma_{S_{2}}$ by their numerical values in (??), we get:

$$
\sigma^{2}=0.09
$$

Therefore, $\gamma_{1}$ and $\gamma_{2}$ can be easily calculated by substituting $r$ and $T$ in (??) and (??) (in our case, $\gamma_{1}=\gamma_{2}$ ):

$$
\begin{aligned}
\gamma_{1} & =0.183 * \sqrt{10} \\
& =\gamma_{2}
\end{aligned}
$$


Thus we get the threshold values $d_{1}, d_{2}$ and $d_{3}$ :

$$
\begin{aligned}
& d_{1}=[0.483 * \sqrt{10} ;-0.474 ;-0.5] \\
& d_{2}=[0.483 * \sqrt{10} ;-0.474 ;-0.5] \\
& d_{3}=[0.579 ; 0.579 ; 0.5]
\end{aligned}
$$

Thus, the algorithm of Drezner (see for instance Hull, 2000) is applied to estimate the value of the cumulative probability in a standardized distribution for $d 1, d 2$ and $d 3$.

We found that:

$$
\begin{aligned}
& N_{2}\left(d_{3}\right)=0.606 \\
& N_{2}\left(d_{1}\right)=0.272 \\
& N_{2}\left(d_{2}\right)=0.272
\end{aligned}
$$

By substituting $S_{1}, S_{2}, K, r, T$ by their numerical values and $N_{2}\left(\underline{\mathrm{d}}_{1}\right), N_{2}\left(\underline{\mathrm{d}}_{2}\right)$ and $N_{2}\left(\underline{\mathrm{d}}_{3}\right)$ by their approximation in Stulz formula(??), we get:

$$
M\left(S_{1}, S_{2}, K, t\right)=12.87
$$

\subsection{Proof of the decision rule}

Initial values of $S_{1}$ and $S_{2}$ are equal. Consequently, we obtain:

$$
C\left(S_{1}, F, t\right)=C\left(S_{2}, F, t\right)=C\left(S_{i}, F, t\right), \text { with } i=1,2
$$

Thus, the expression $\gamma M X\left(S_{1}, S_{2}, F, t\right)-C\left(S_{i}, F, t\right)$ can be rewritten as (by assumption, $\gamma>0)$ :

$$
\frac{(2 \gamma-1)}{\gamma} C\left(S_{i}, F, t\right)-M\left(S_{1}, S_{2} F, t\right)
$$

If $\gamma<\frac{1}{2}$, then $\frac{(2 \gamma-1)}{\gamma} C\left(S_{i}, F, t\right)-M\left(S_{1}, S_{2} F, t\right)<0$. If $\gamma=1$, then $\frac{(2 \gamma-1)}{\gamma} C\left(S_{i}, F, t\right)-$ $M\left(S_{1}, S_{2}, F, t\right)>0$. As options values $C$ and $M$ are not function of $\lambda$, the function $f(\lambda)=\frac{(2 \gamma-1)}{\gamma} C\left(S_{i}, F, t\right)-M\left(S_{1}, S_{2}, F, t\right)$ is continuous and strictly increasing in $\gamma$ on the interval $] 0,1[$ as:

$$
\left.\frac{\partial f(\lambda)}{\partial \gamma}=\frac{1}{\gamma^{2}} C\left(S_{i}, F, t\right)>0 \forall \gamma \in\right] 0,1[
$$

Due to a simple intermediate value argument, there exists a unique threshold value $\bar{\gamma}$ such that: a rule is preferred if $\gamma$ is lower than $\bar{\gamma}$. Otherwise, a standard is preferred.

Therefore, the unique threshold value $\bar{\gamma}$ such that $\bar{\gamma} M X\left(S_{1}, S_{2}, F, t\right)$ equals $C\left(S_{i}, F, t\right)$ 
is defined by:

$$
\bar{\gamma}=\frac{C\left(S_{i}, F, t\right)}{M X\left(S_{1}, S_{2}, F, t\right)}
$$

\subsection{Valuation of waiting to enact}

In the continuation region, the Bellman equation can be re-written as:

$$
r F(P, t)=E[d F]
$$

That is, over a time interval $d t$, the total expected return on the creation of law opportunity $r F(P)$ is equal to the expected benefits growth rate. Suppose that $P$ follows the process of equation (4), and consider a function $F(P, t)$ that is at least twice differentiable in $P$. We expand $d F$ using Ito's Lemma:

$$
\begin{aligned}
d F= & \left\{\alpha P F_{P}+\frac{\sigma^{2}}{2} P^{2} F_{P P}+[F((1-\phi) P)-F(P)] \lambda\right\} d t+\sigma P F_{P} d z \\
& +[F((1-\phi) P)-F(P)](d N-\lambda d t)
\end{aligned}
$$

With $E(d z)=0$ and $E(d N)=\lambda d t$, we get:

$$
\begin{gathered}
E(d F)=(\alpha-\lambda \phi) P F_{P} d t+\frac{\sigma^{2}}{2} P^{2} F_{P P} d t+F((1-\phi) P) \lambda d t-F(P) \lambda d t \\
(\alpha-\lambda \phi) P F_{P} d t+\frac{\sigma^{2}}{2} P^{2} F_{P P} d t+F((1-\phi) P) \lambda d t-F(P) \lambda d t-r F d t=0
\end{gathered}
$$

Hence, equation (??) can be rewritten as:

$$
\frac{\sigma^{2}}{2} P^{2} F_{P P}+\alpha P F_{P}+\lambda F((1-\phi) P)-(r+\lambda) F=0
$$

$r=\delta+\alpha-\lambda, 0 \leq \alpha \prec r$ and $\delta>0$. The solution must also follows three boundary conditions.

$$
\begin{gathered}
F(0)=0 \\
F\left(P^{*}\right)=P^{*}-I \\
F^{\prime}\left(P^{*}\right)=1
\end{gathered}
$$

The first condition (9)is that if $P=0$, then from the mixed Brownian jump process (4), we know that $P$ will never be positive. Consequently, the value to wait is nil and the value of invest immediately negative. (9) refers to the case where there is no policy purpose. 
At the value matching condition (10) $P^{*}$, lawmakers are indifferent between waiting and enacting the law. The "smooth pasting" condition (11) comes from the continuity property of the benefits evolution. This condition is implied by (11). The option value has to be continuous, such that the legislator can create law at any moment, and particularly at $P^{*}$. Thus, the curve of the option value $F(P)$ has to be tangent to $P-I$ at $P^{*}$. The solution is of the form:

$$
F(P)=A \cdot P^{\beta_{1}}
$$

with $\beta_{1}$ the positive solution of (with $r-\delta=\alpha-\lambda$ ):

$$
\frac{1}{2} \sigma^{2} \beta(\beta-1)+(r+\lambda-\delta) \beta-(r+\lambda)+\lambda(1-\phi)^{\beta}=0 \text { with } \lambda>0
$$

If $\phi=1$, the positive solution of (13) is:

$$
\beta_{1}=\frac{1}{2}-\frac{(r+\lambda-\delta)}{\sigma^{2}}+\sqrt{\left(\frac{r+\lambda-\delta}{\sigma^{2}}-\frac{1}{2}\right)^{2}+2 \frac{(r+\lambda)}{\sigma^{2}}}
$$

Thus,

$$
S^{*}=\frac{\beta_{1}}{\beta_{1}-1} K
$$

and,

$$
A=\frac{S^{*}-K}{\left(S^{*}\right)^{\beta_{1}}}=\frac{\left(\beta_{1}-1\right)^{\beta_{1}-1}}{\left(\beta_{1}\right)^{\beta_{1}} K^{\beta_{1}}}
$$




\section{References}

[1] Ayres, Ian, 2005, Optional Law: The Structure of Legal Entitlements, Chicago, IL: University of Chicago Press.

[2] Bar-Gill, Oren, 2005, "Pricing Legal Options: A Behavioral Perspective," 1 Review of Law and Economics 203-240.

[3] Baker, G., Gibbons, R. and Murphy, K.J., 1999, "Informal Authority in Organizations," 15 Journal of Law, Economics and Organization 56-73.

[4] Black, F. and Scholes M., 1973, "The Pricing of Options and Corporate Liabilities," 81 Journal of Political Economy, 637-59.

[5] Cooter, Robert and Rubinfeld, Daniel L., 1989, "Economic Analysis of Legal Disputes and Their Resolution," 27 Journal of Economic Literature 1067-1097.

[6] Diver, Colin S., 1983, "The Optimal Precision of Administrative Rules," 93 Yale Law Journal 65-109.

[7] Dixit, Avinash K. and Pindyck, Robert S., 1994, Investment Under Uncertainty, Princeton, NJ: Princeton University Press.

[8] Drezner, Z., "Computation of the Bivariate Normal Integral, " 32 Mathematics of Computation 277-79.

[9] Ehrlich, Isaac and Posner, Richard A., 1974, "An Economic Analysis of Legal Rulemaking," 3 The Journal of Legal Studies 275- 86.

[10] Fon, Vinci and Parisi, Francesco, 2004, "Codifications and the Optimal Specificity of Legal Rules," George Mason University Research Paper 04-32.

[11] Goffin, Robert, 1995, "Options Réelles sur Maximum ou Minimum," 19 Banques et Marchés, 17-26.

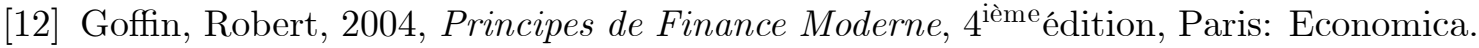

[13] Grundfest, Joseph A., and Huang Peter H., 2004, "The Unexpected Value of Litigation," 58 Stanford Law Review 1267-336.

[14] Hart H.L.A., 1994, The Concept of Law, $2^{\text {nd }}$ Edition, New York: Oxford University Press, 1961, 1994. 
[15] Hull, John, 2004, Options, Futures and Other Derivatives, $5^{\text {th }}$ Edition, Upper Saddle River, NJ: Prentice Hall, Pearson Education.

[16] Johnson, Herb, 1987, "Options on the Maximum or Minimum of Several Assets," 22 Journal of Financial and Quantitative Analysis 277-283.

[17] Johnston, Scott Jason, 1991, "Uncertainty, Chaos and the Tort Process," 76 Cornell Law Review 341-400.

[18] Johnston, Scott Jason, 1995, "Bargaining Under Rules Versus Standard," 11 Journal Law, Economics, and Organization 256-281.

[19] Jones, Robert A. and Ostroy, Joseph M., 1984, "Flexibility and Uncertainty," 51 The Review of Economic Studies 1, 13-32.

[20] Kaplow, Louis, 1992, "Rules versus Standards: an Economic Analysis," 42 Duke Law Journal 557-629.

[21] Kaplow, Louis, 1995, "A Model of Optimal Complexity of Law," 11 Journal of Law, Economics, and Organization, 150-63.

[22] Kaplow, Louis, 1999, "General Characteristics of Rules," in Encyclopedia of Law and Economics, ed. By B. Bouckaert and G. DeGeest, Edward Elgar, Cheltenham.

[23] Landes, William M. and Posner, Richard A., 1975, "The Independant Judiciary in an Interest-Group Perspective," 18 Journal of Law and Economics 875-901.

[24] Landes, William M. and Posner, Richard A., 1976, "Legal Precedent: A Theoretical and Empirical Analysis,"19 Journal of Law and Economics 249-307.

[25] LoPucki, Lynn M., 1996, The Death of Liability, 106 Yale Law Journal 1-92.

[26] Mahoney, Paul G. and Sanchirico, Chris William, 2005, "General and Specific Legal Rules," 161 Journal of Institutional and Theoretical Economics 329.

[27] Malik, Arun S., 1990, "Avoidance, Screening and Optimum Enforcement," 21 RAND Journal of Economics 3, 341-353.

[28] McDonald, Robert and Siegel, Daniel, 1986, "The Value of Waiting to Invest," 101 Quarterly Journal of Economics 707-28.

[29] Merton, Robert C., 1976, "Option Pricing When Underlying Stock Returns Are Discontinuous," 3 Journal of Financial Economics 125-44. 
[30] Merton, Robert C., 1973, "Theory of Rational Option Pricing," 4 Bell Journal of Economics and Management Science 141-84.

[31] Montesquieu, Charles de Secondat, 1748, De l'Esprit des Lois, Paris: GF Flammarion, 1993.

[32] Parisi, Francesco, Fon, Vinci and Ghei, Nita, 2004, "The Value of Waiting in Lawmaking," 18 European Journal of Law and Economics 131-48.

[33] Pistor, Katharina and Xu, Chengang, 2003, "Law Enforcement Under Incomplete Law: Theory and Evidence From the Financial Market Regulation," Columbia Law and Economics Working Paper No. 222, http://ssrn.com/abstract=396141.

[34] Pistor, Katharina and Xu, Cheng-Gang, 2002a, "Incomplete Law - A Conceptual and Analytical Framework and its Application to the Evolution of Financial Market Regulation," Columbia Law and Economics Working Paper No. 204, http://ssrn.com/abstract $=310588$.

[35] Pistor, Katharina and Xu, Cheng-Gang, 2002b, "Fiduciary Duty in Transitional Civil Law Jurisdictions Lessons from the Incomplete Law Theory," ECGI Law Working Paper No. 01/2002, http://ssrn.com/abstract=343480.

[36] Posner, Richard A., 1999, The Problematics of Moral and Legal Theory, Cambridge, MA: Harvard University Press.

[37] Posner, Richard A., 2003, Economic Analysis of Law, $6^{\text {th }}$ Edition, New York: Aspen.

[38] Piatecki, Cyrille, 2004, "Introduction aux Mathématiques de l'Economie Stochastique en Temps Continu", Document de travail du Laboratoire d'Economie d'Orléans.

[39] Spier, Kathryn E.,1994, "Settlement Bargaining and the Design of Damage Awards," 10 Journal of Law, Economics and Organization 84-95.

[40] Stigler, George J., 1971, "The Theory of Economic Regulation," 2 Bell Journal of Economics and Managment Science 3.

[41] Stulz, René M., 1982, "Options on the Minimum and the Maximum of Two Risky Assets," 10 Journal of Financial Economics 161-85. 